\title{
Generator Voltage Stabilisation for the Series-Hybrid Vehicle
}

\author{
Paul Stewart ${ }^{a}$ Richard Cowley ${ }^{b}$ \\ "Corresponding Author: Department of Electronic and Electrical Enginetring. University of Sheffield. Mappin St. Sheffield U.K. \\ e-mail:p.stewartoshef.acuk tel: +4/40)11/422258/1. \\ far: 1446$) 1142285196$ \\ Department of Electronic and Ficctrical Engineering, University of Sheffield. Mappin St. Sheffield U.K.
}

\begin{abstract}
T'his paper presents a simple, robust controller for use in speed control of an internal combustion engine for serieshybrid electric vehicle applications. Farticular referenee is made to the stability of the rectified DO link voltage under load disturbance and potentially inaceurate system models. In the system under consideration, the primary power souree is a 4-eylinder normally aspirated gasoline internal combustion engine, which is mechanically coupled to a three-phase permanent magnet AC generator. T'he generated AC voltage is subsequently rectified to supply a lead-acid battery, and permanent magnet traction motors via three-phase full bridge power electronic inverters. Two complementary performance objectives exist. Firstly to maintain the internal combustion engine at its optimal operating point, and secondly to supply a stable $42 \mathrm{~V}$ supply to the traction drive inverters. Achievement of these goals minimises the transient energy storage requirements at the DC link, with a consequent reduetion in both weight and cost. These objectives imply constant velocity operation of the internal combustion engine under external load disturbances and changes in both operating conditions and vehicle spoed set-points. An electronically operated throttle allows closed loop engine velocity control. System time-delays and non-linearities render closed loop control design extremely problematic. A model based controller is designed and shown to be robust in controlling the DC link voltage, resulting in well-conditioned operation of the hybrid vehick.
\end{abstract}

Key words: Automotive, Model-Reference Control, 'I'ime-l)elay, Hybrid Vehicles

\section{Introduction}

The series-hybrid electric vehicle drivetrain [1] consists of [2] petrol internal combustion (IC) engine, AC generator, DC rectification, battery energy storage, three-phase inverter and traction drives (Fig. 1). The stability of the DC link between the

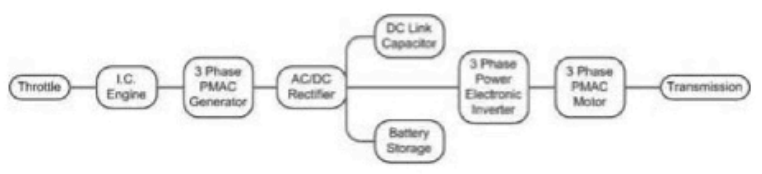

Fig. 1. Series-hybrid electric vehicle drivetrain.

$\mathrm{AC} / \mathrm{DC}$ rectifier and the traction motor inverter drive is operationally critical whether the prime mover be a petrol or diesel IC engine [3]. Firstly a prime objective for operation of the traction drives is to deliver smooth, ripple-free torque. Controllers for this purpose rely on a stable DC link supply. Of particular importance is its ability to reject both dynamic and static loads from the traction drives and also an ability to absorb excess energy under regenerative braking regimes. A direct advantage of maintaining the integrity of the DC link voltage is the associated maintenance of the IC engine at its optimal operating point in terms of fuel efficiency and pollutants [3]. Again, the rejection of dynamics from drive loading is instrumental in achieving this gosll. 
The control system for the series-hybrid electrie vehicle (SEV) has both cascaded and nested structures, and consists of a velocity set-point controller for the IC engine via an olectronically actuated throttle, and current control loops around the traction drive units (Fig. 2). There are a variety of power

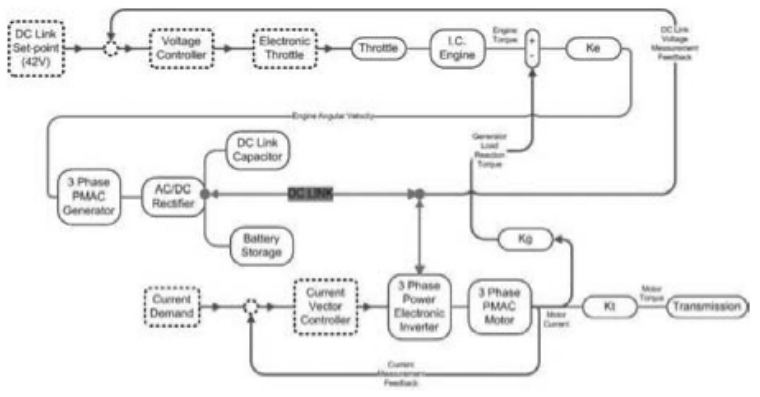

Fig, 2. Series-hybrid electric vehicle control stucture

control strategies applied to hybrid clectric vehicle (HEV) powertrains [4], [5] which generally try to achieve a number of goals in a four cost function [2],

- maximise fucl economy

- minimise emissions

minimise system costs

maximise driving performance.

\section{Choice of operating point}

Of particular importance in this analysis is the twin goals of maximising fucl conomy and minimising emissions such as hydeocarbons (HC) and carbon monoxide (CO). The experimental fucl consumption and efficioney of a typical [6] four eylinder four-stroke spark ignition engine with a nominal size of $1600 \mathrm{cc}$. running on 91 octane gasoline are shown in figures $(3,4)$.

Brake thermal efficiency (BTE) is calculated as

$B T E=\frac{P e}{m_{j} L H V}$,

where $P e$ is effective power, $\dot{m}_{f}$ is the fuel mass flow rate, and $L H V$ the lower heating value of the fuel. $B$ the engine fuel consumption and thermal efficiency, have a corrosponding optimal specd of 1800 rpm with respect to minimisation of fucl consumption and maximisation of efficiency.

With respect to emissions, CO decreases steadily through the experimental range, whoreas $\mathrm{HC}$ is relatively stable above $1600 \mathrm{rpm}$. The choice of operating point thus presents a tradeoff between objectives. HC emissions require an operating point above

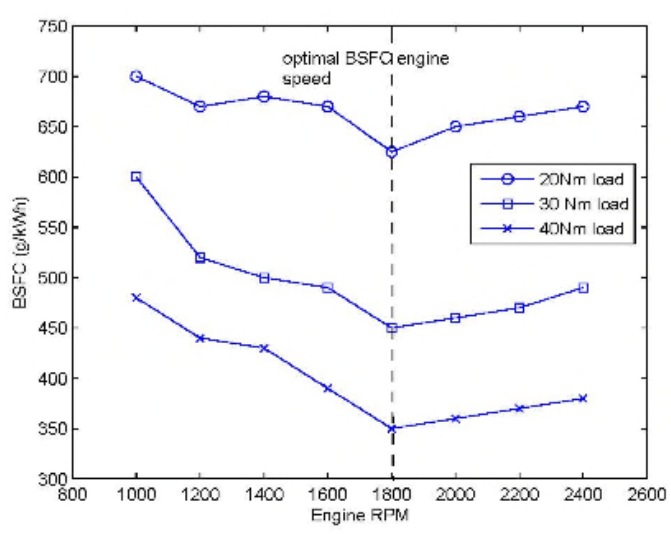

Fig. 3. Fngine fuel consumption at varying loads

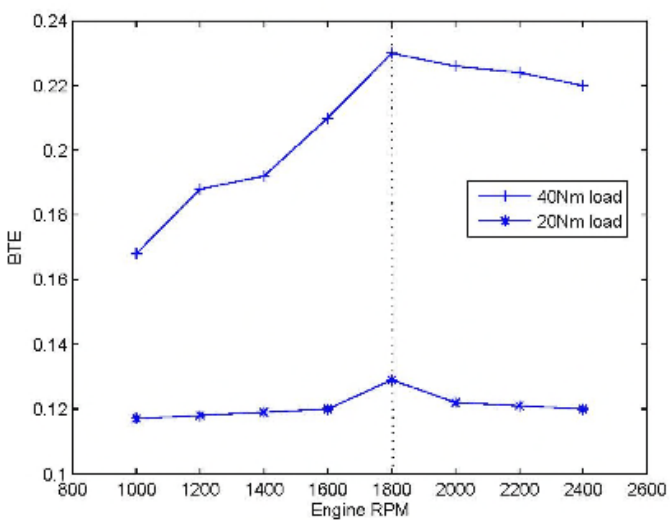

Fig. 4. Engine brake thermal efficiency at varying loads

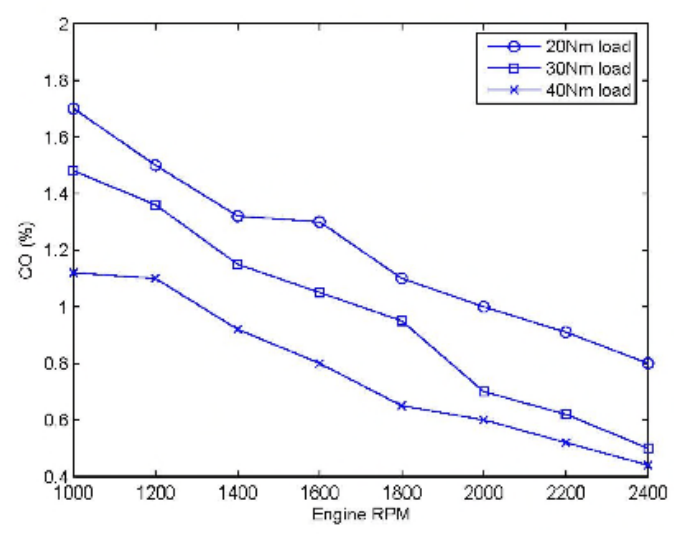

Fig. 5. Exhaust CO percentage at varying loads

$1600 \mathrm{rpm}$, fuel consumption and officiency is optimal at $1800 \mathrm{rpm}$. CO emissions are declining by approximately $0.05 \% / 200 \mathrm{rpm}$ in this region. It was thus decided to trade-off $\mathrm{CO}$ emissions and fuel economy 


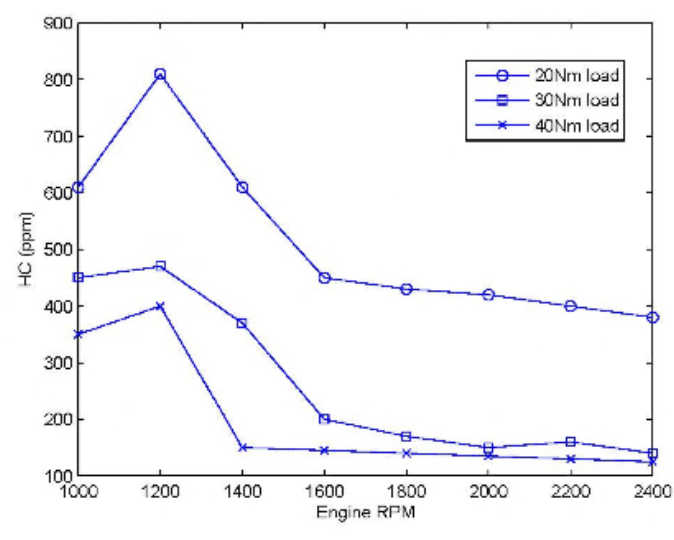

Fig. 6. Exhanust. HC (ppru) at varying loads

at 2000rpm, gaining a reduction in emissions, for a small reduction in efliciency.

\section{Generator voltage control}

Stable generator output voltage requires control authority over engine speed. A number of methodologies for idle speed control (ISC) have been presented in the literature [10]. The primary motivation for ISC is to maintain a selcted idle specd while rejecting torque disturbances such as power steering, altermator and automatic transmission loads. In most production vehicles, the amount of air is controlled by a throttle bypass valve, sometimes augmented by additional valves actuated by an accessory load signal [11]. Altcrnatively, it is possible to directly control the throttle by direct electronic means rather than by mechanical linkages [12],[13]. Air control provides large authority over the engine, however it is subject to intake manifold dynamics and intake-to-torque time delays. Direct control of the spark ignition timing provides a high bandwidth-low delay approach. However spark control has rather linited authority since excessive retardation of the ignition can cause combustion instabilities.

In the hybrid electric vehicle under consideration hore, it is dosired to produce a low-cost implomentation of the control structure, and hence direct control of the throttle by electronic means is identified as the preferred technology if the inherent systom delays can be overome to produce a reliable speed controller. This is reinforced by the fact that a typical production ISC controller includes a PID loop for air control, a proportionel loop for the spark control, fecdforward loop for accessory loads, and other ad hoc loops for a variety of envirommental compensation schemes.

The main characteristics of spark ignition engines is that they are highly nonlinear with significant time delay between throttle and torque production. The main objective of this research is to produce lowcost stable engine angular velocity control with good disturbance rejection characteristics. Torque based control methods [14], [15], generally rely on high precision feedback data such as cylinder pressure sensors, however cycle-to-cycle fluctuations coupled with low rosolution crank angle measurements can pose problems for the stability of any closed loop control scheme. This often leads to the complicated implementation of further inner compensation schemes.

\subsection{Smith Predictor}

The general limitation of tuming rules for PID controllers is that thoy are dorived for dolay-froe systems. For the system under consideration, the compound timo delay betwoen control actuator signal and torque production initiation at $2000 \mathrm{mpm}$ was found experimentally to be $980 \mathrm{~ms}$ with a variability of $\pm 50 \mathrm{~ms}$. Under such circumstances, a PID controller is extremely difficult to tume by standard tuming rules. A stible controller was eventually indentified by trial and cror with hardware in the loop. The performance of the controller is shown in figure 7. The experimental setup is discussed more fully in later sections of this paper. The regulator was attempting to stabilise the generated de voltage at $42 \mathrm{~V}$, the performance was as follows:

- Mean voltage $39.4 \mathrm{~V}$

Standard deviation $3.27 \mathrm{~V}$

Of particular note is the $9 \mathrm{~s}$ delay initialising to a quasi steady state condition. The chosen controller was a PD type with gains of 0.04 and 0.01 respectively. Any larger gain combinations or addition of an integral component to the controller resulted in better mean voltage values but incroasing oscillatory response. In figure 8 the PID gains have been set at $0.04,0.01$ and 0.01 respectively. The integral component has improved the mean voltage at the expense of large voltage ripple. The performance of this controller was:

Mean voltage $41.83 \mathrm{~V}$

Standard deviation $4.38 \mathrm{~V}$ 

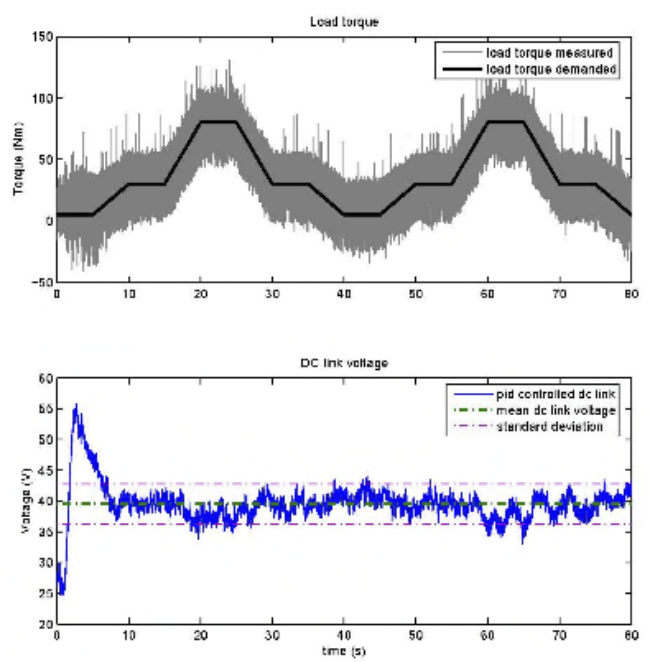

Fig. 7. Regulation of hybrid de link voltage with PD controller

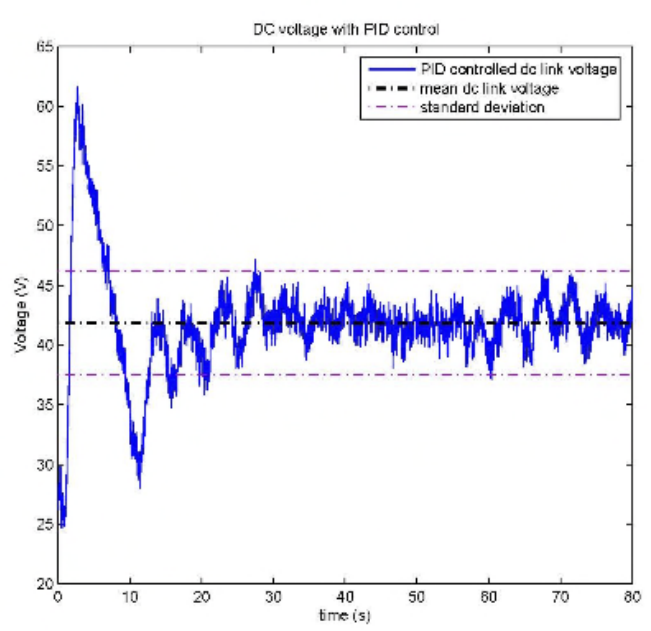

Fig. 8. Riegulation of hybrid dc link voltage with I'II) controller

This motivates the design of a predietive controller such as the Smith Predictor [8], [9]. The predictor generally utilises a model of the plant characterized into a lincar transfor function accompanied by a time delay. A model is used to simulate the delayed and undelayed states of the plant, subsequently the real plant output is canceled by the delayed state, and the undelayed state is used as the feedback signal for the plant controller (fig 9). The transfer function of the plant and Smith Predictor can be written as [7]

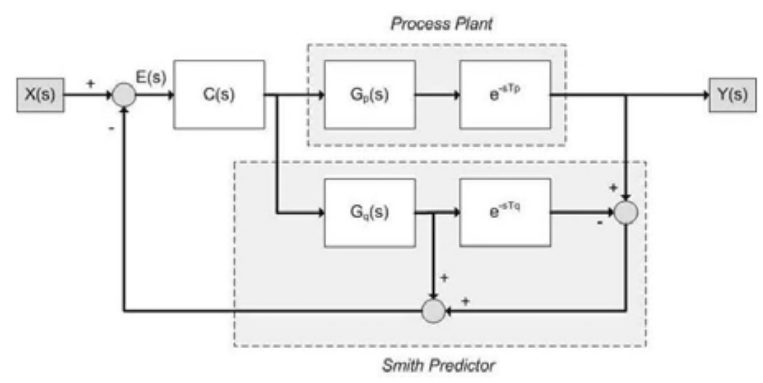

Fig. 9. Smith Predictor control structure for system with time delay.

$\frac{Y(s)}{X(s)}=$

$\frac{C(s) G_{p}(s) e^{-s T_{p}}}{1+C(s) G_{q}(s)+C(s)\left[G_{p}(s) e^{-s T_{p}}-G_{q}(s)^{-s T_{q}}\right]}$

Hence if the model parameters exactly match the plant, equation (2) simplifies to

$\frac{Y(s)}{X(s)}=\frac{C(s) G_{p}(s)}{1+C(s) G_{p}(s)} e^{-s T_{p}}$.

The predictor romoves the time delay effects from the control loop, converting the corresponding control design to a delay free problem. The process model $G_{p}(s)$ contains a dead-time $T_{p}>0$, with controller $C(s)$, and a loop containing a process model $G_{q}(s) e^{-s^{\prime} q}$.

The feedback signal is given by

$\begin{aligned} Y_{F B}(s) & =G_{q}(s) E(s) C(s) \\ & +\left(G_{p}(s) e^{-s T_{p}}-G_{q}(s) e^{-s T_{q}}\right) E(s) C(s)\end{aligned}$

Assuming perfect modeling of the plant and delay, then

$Y_{F B}=G_{q}(s) E(s) C(s)$

Since

$E(s) C(s)=\frac{1}{G_{p}(s) e^{-s T T_{p}^{\prime}}} Y(s) \quad$ and,
$G_{q}(s)=G_{p}(s)$

then,

$Y_{F B}=G_{q}(s) \frac{1}{G_{p}(s) e^{-s T_{p}}} Y(s)=e^{s T_{p}} Y(s)$.

Thus in the time-domain, $Y_{F B}(t)=y(t+T)$ which is the prediction of the output signel. 


\subsection{Smith predictor engine model}

The implementation of a predictive controller to overcome the significant time delays inherent in the engine requires a mold which is representative of the engine dynamics and time delay [10]. In this case, for simplicity and ease of implementation, the adopted model (figure 10) was a set of structures linearised [16] around the operating speed of interest, which relates output torque changes to changes in fuel, spark and throttle [17].

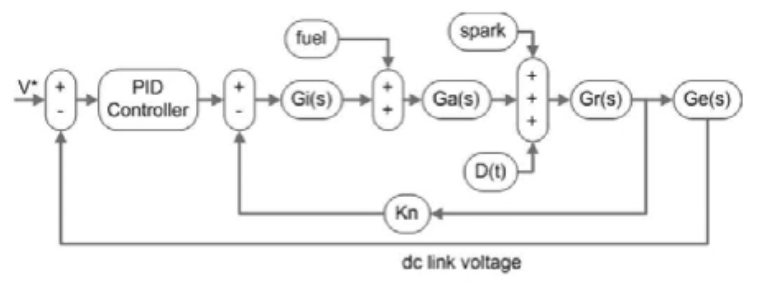

Fig. 10. Linearised engine / generator model

Where $V *$ is the required dc link voltage, $G i(s)$ is the inlet manifold dynamics, $G a(s)$ is the combustion delay, $G r(s)$ is the lumped rotational dynamies for the combined system, $G e(s)$ is the generator electrical dynamies, $K n$ is the pumping dynamies, and $D(t)$ is the time-varying load from the traction motors which are reflected into the ic engine as reaction torque from the generator. Tests for obtaining the model parameter values [18], consisting of throttle, spark and load inputs resulting in peturbation response of the generator voltage level. This method enables direct evaluation of the model parameter values.

In particular, tests were carried out to produce linearised models not only at the nominal opcrating point of $2000 \mathrm{rpm}$, but vis designed experiments between 1500-2000rpm. This enabled the implementation of a parameter lookup table giving a lincarised model over a range of operating conditions. The parameters of the model are currently subject to a confidentiality agreement.

\section{Results}

The experimental results presented in this paper (figures $7,8,12$ ) were carried out under PID or PD control which was tracking a $42 \mathrm{~V}$ voltage command. In each case, the disturbance torque reflected back to the generator followed the profile presented in figures 7,12 , with a peak disturbance of $80 \mathrm{Nm}$. The implementation of the predictive controller improves the generator stability considerably, from a worst case of mean voltage $39.4 \mathrm{~V}$ and standard deviation of $4.38 \mathrm{~V}$ to a mean voltage of $41.64 \mathrm{~V}$ and standard deviation of $1.2 \mathrm{~V}$ for the predictor compensated system (figure 12.

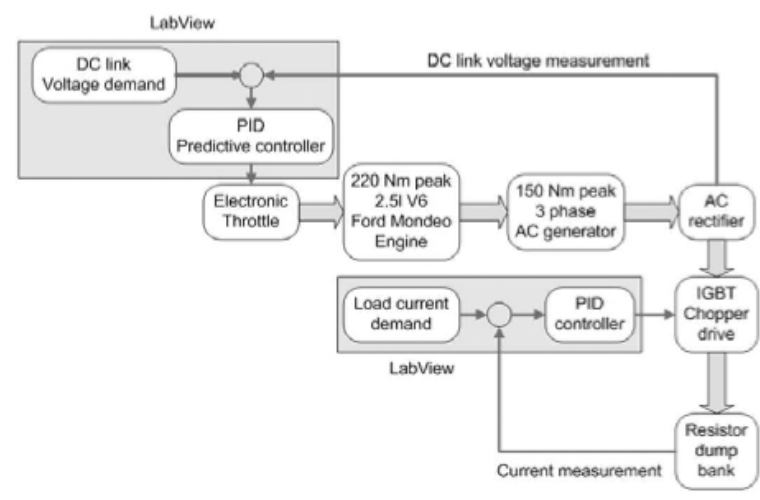

Hig. 11. Hxperimental rig,
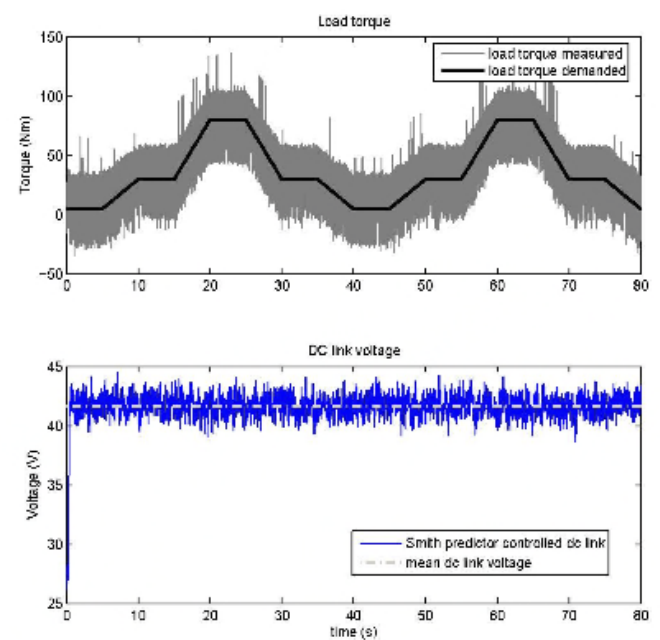

Fig. 12. Hingine torque disturbance and generator output voltage.

The implementation of the Smith Prodietor significantly rolued the voltage ripple genorated by the hybrid powertrain. In particular the use of a simplified linearised model has shown itself to be effective, especially considering the problems of integration and development into a real-time controller.

\section{References}

[1] Chan C.C." "An overview of electric vehicle technology", l'roceedings of the Ititit, Vol. 81, no. 9, pp. 1202-1213, 1993. 
[2] Chau K.T, and Wong Y.S., "Overview of power management in hybrid electric vehicles", Energy Conversion and Management, vol. 43, pp. 1953-1968, 2002.

[3] Al-Atabi MT, Yusaf 'TF, "Experimental investigation of a single cylinder diesel engine as a hybrid power unit for a series hybrid electric vehick", Proce. IFEE Conferenece on Globalising Research and Development in Electrical and Electronics Engineering, 16-17th July 2002, Shah Alam, Malaysia, IE'E Cat. No. 02tX598, 261-4.

[1] Van Mierlo J. "Views on hybrid drivetrain power management", Proceedings of the 17 th International thectric Vehicle Symposium, 2000, CD Rom

[5] Beretta 1., "New tools for energy efficiency evaluation on hybrid system architecture", Proceedings of the $f \gamma_{\text {th }}$ International Electric Vehiche Symposium, 2000, CD Riom

66 Sayin C., Hirtrunc H.M., Hoso\% M., Kilicaslan I. and Canacki M., "Performance and exhaust emissions of a gasoline engine using artificial neural network", Applied Thermal Engineering, Vol. 27 , pp. 46-54, 2007.

[7] Huang J. J. and DeBra D. B., "Automatic SmithPredictor tuning using optimal parameter mismatch", IEEE Transactions on Control Systems Technology, vol, 10, no. 3, p), 447-459 May 2002

|8| Smith O. J. M. "Closer control of loops with dead time" Chem. Fing. Progress, vol. 53, no. 5, pp. 217-219, 1957.

19| Smith O..l.M. "Feedback Control Systems", McGraw. Hilh, New York, 1958.

[10] Hrovat D. and Sun J., "Models and control methodologies for $\mathrm{IC}$ engine idle speed control design", Control Engineering Pructice, Vol. 5, no. 8, pp. 1093$1100,1997$.

111| Probst C.O., "Ford fuel injection and elect.ronic engine control", Robert Bentley Publishers, Cambridge, USA, 1992

[12] Rossi C., Tilli $A$, and Toniclli $A$., "Robust control of a throttle body for drive by wire operation of automotive engines", IEEE Transactions on Control Systems Technology, Vol. 8, no, 6, pp. 993-1002, 2000.

[13] Pavkovic D., Deur J., Jansz M. and Peric N., "Adaptive control of automotive electronic throttle", Control Engineering Practice, vol 14., Pp. 121-136, 2006.

[14] Jaine T., Chamaillard Y., Charlet A., IIigeliu P. and Perrier C., "High frequency IVIFI" estimation, filtering lor torque based SI engine control", Sociely of Automotive Engineers, Paper 2002-01-1276.

|15| Chamaillard Y., Higclin P. and Charlet $\Lambda$. " $\Lambda$ simple method for robust control design, application on a non-linear and delayed system: engine torque control", Control Fngineering Praclice, Vol. 12, pp. 417-429, 2004.

|16| Cook ,J.A. and Powell B.K., "Modelling of an internal combustion engine for control analysis", IFEF Control Systems Maqazine, Vol. 8, no. 1, pp. 20-26, 1998.

[17] Howell M.N. and Best. M.C., "On-line PID tuning for engine idle-speed control using continuous action reinforcement learning antomota", Control Engineering Pructice, Vol. 8, pp. 147-154, 2000.

$|18|$ Coats F.t.. and Fruchette R.ID., "Dynamic Hingine Models for Control Development - I'art II", Apptication of Control Theory in the Automotive Industry, Interscience, Geneva, Switzerland, 1983. 